Article

\title{
The Present SP Tests for Determining the Transition Temperature TSP on "U" Notch Disc Specimens
}

\author{
Karel Matocha ${ }^{1, *}$, Ondrej Dorazil ${ }^{2}$ and Roger Hurst ${ }^{3}$ \\ 1 Department of Material Engineering, Faculty of Metallurgy and Materials Engineering, \\ VŠB-Technical University of Ostrava, 17. Liostopadu 2172/15, 70800 Ostrava, Czech Republic \\ 2 MATERIAL \& METALLURGICAL RESEARCH Ltd., Pohranicni 31, 70300 Ostrava-Vitkovice, \\ Czech Republic; ondrej.dorazil@mmvyzkum.cz \\ 3 Institute of Structural Materials, College of Engineering, Swansea University, Swansea SA2 8PP, UK; \\ r.c.hurst@plnet.nl \\ * Correspondence: matocha.karel@email.cz; Tel.: +420-606-750-442 \\ Academic Editor: Yong-Cheng Lin \\ Received: 31 March 2017; Accepted: 27 April 2017; Published: 3 May 2017
}

\begin{abstract}
The principal difference between the small punch (SP) testing technique and standardized impact testing lies in the fact that the SP tests carried out in accordance with CWA 15627 Small Punch Test Method for Metallic Materials use disc-shaped test specimens without a notch. Especially in tough materials, the temperature dependence of SP fracture energy $\mathrm{E}^{\mathrm{SP}}$ in the transition area is very steep and lies close to the temperature of liquid nitrogen. In this case, the determination of SP transition temperature $\mathrm{T}_{\mathrm{SP}}$ can lead to significant errors in its determination. Efforts to move the transition area of penetration testing closer to the transition area of standardized impact tests led to the proposal of the notched disc specimen $8 \mathrm{~mm}$ in diameter and $0.5 \mathrm{~mm}$ in thickness with a " $\mathrm{U}$ " shaped notch $0.2 \mathrm{~mm}$ deep in the axis plane of the disc. The paper summarizes the results obtained to date when determining the transition temperature of $\mathrm{SP}$ tests $\mathrm{T}_{\mathrm{SP}}$, determined according to CWA 15627 for material of pipes made of P92, P22, and a heat treated 14MoV6-3 steel in the as delivered state. Although the results obtained confirmed the results of other works in that the presence of a notch in a SP disc is insufficient to increase the transition temperature significantly and certainly not to the values obtained by Charpy testing, comparison of the different behaviors of the alloys tested reveals some evidence that the notch reduces the energy for initiation. This implies that the test on a notched disc is more a test of crack growth and would be a useful instrument if included in the forthcoming EU standard for SP testing.
\end{abstract}

Keywords: small punch testing; SP transition temperature $\mathrm{T}_{\mathrm{SP}}$; notched disc specimen; plane disc specimen; impact energy; fracture appearance transition temperature (FATT); ductile brittle transition temperature (DBTT); transition temperature (TT)

\section{Introduction}

CWA 15627 Part B: A Code of Practice for Small Punch Testing for Tensile and Fracture Behavior ("the Code") describes the procedures recommended for determination of yield stress YS, ultimate tensile strength UTS, DBTT (measured by fracture appearance transition temperature (FATT) and/or absorbed energy transition temperature (TT) (for example 41J) and fracture toughness $\mathrm{J}_{\mathrm{IC}}$ of the metallic materials from the results of SP tests [1,2].

DBTT expressed as FATT is correlated according to the Code with $\mathrm{T}_{\mathrm{SP}}$ (SP transition temperature), determined from the results of SP tests in the temperature range $-193{ }^{\circ} \mathrm{C}$ to $+23{ }^{\circ} \mathrm{C}$ in the form [1-4]:

$$
\mathrm{T}_{\mathrm{SP}}=\alpha \mathrm{FATT}_{\text {Charpy }} \text { or } \mathrm{FATT}_{\text {Charpy }}=\mathrm{T}_{\mathrm{SP}} \beta+\mathrm{A}
$$


Typical values for $\alpha$ for structural steels have been reported to be around $0.35[5,6]$ indicative of much lower transition temperatures realized during the SP test than with conventional Charpy methods. The SP transition temperature $\mathrm{T}_{\mathrm{SP}}$ is determined according to the Code as the temperature where $\mathrm{E}^{\mathrm{SP}}$ has its mean value of the highest and the lowest values in the transition region, by intersecting the smooth curve fitted from the energy versus temperature dependence of fracture energy $\mathrm{E}^{\mathrm{SP}}$ [1]. The $\mathrm{SP}$ fracture energy $\mathrm{E}^{\mathrm{SP}}$ is determined by integration of the force-displacement curve up to fracture [1]:

$$
\mathrm{E}^{\mathrm{SP}}=\int_{0}^{u_{f}} \mathrm{~F}(\mathrm{u}) \mathrm{du}
$$

where $\mathrm{u}_{f}$ is defined according to Code as the punch displacement at $20 \%$ load drop after maximum $\operatorname{load} \mathrm{F}_{\mathrm{m}}\left(\mathrm{F}_{\mathrm{f}}=0.8 . \mathrm{F}_{\mathrm{m}}\right)$.

Multiple load drops are observed from time to time at load-punch displacement curve at the SP tests carried out at lower temperatures [4,7]. By monitoring the bulged surface of the disc during the SP test with a camera in author laboratory [8] it has been shown, that the occurrence of the first load drop is a consequence of the initiation of the first circumferential crack with the following load drop associated with the propagation of further radial cracks. In such cases, the SP fracture energy $\mathrm{E}^{\mathrm{SP}}$ should be calculated as the area under the load-punch displacement curve up to first load drop. However, the determination of SP transition temperature $\mathrm{T}_{\mathrm{SP}}$ in accordance with CWA 15627 and from energy for the initiation of the first crack was found to be insignificant $[4,8]$.

The principal difference between the SP testing technique and standardized impact testing lies in the fact that the SP tests carried out in accordance with the Code use disc-shaped test specimens without a notch. Especially in tough materials, the temperature dependence of fracture energy in the transition area is very steep and lies close to the temperature of liquid nitrogen. The procedure recommended in the CWA for the determination of $\mathrm{T}_{\mathrm{SP}}$ can, in this case, lead to significant errors in its determination [9]. Efforts to move the transition area of small punch testing closer to the transition area of standardized impact tests led to the proposal of the notched disc specimen. Up to the present, only very few authors have introduced a notch in small punch testing, mostly in relatively recent studies [9-12]. However, the introduction of a sharp circular notch with a notch tip radius $<5 \mu \mathrm{m}$ and of diameter equal to the punch diameter with the intention of maximizing the notch tip load equally around the notch circumference did not result in the displacement of SP transition temperature $\mathrm{T}_{\mathrm{SP}}$ towards the FATT obtained from conventional Charpy V notch tests [13]. The most recent attempts in the authors' laboratories to investigate the effect of notch geometry on SP transition temperature have used both scratched (an orthogonal cross of $50 \mu \mathrm{m}$ [14]) and a diametral EDM notch $200 \mu \mathrm{m}$ deep [15] on a disc removed from reactor pressure vessel steel. Although both types of notch contributed significantly to the initiation of the fracture process they were found to have little effect on the ductile brittle transition temperature, even with high strain rate testing closer to Charpy conditions. Nevertheless, it is under consideration to include notched disc testing in the proposed standard on $\mathrm{SP}$ testing and additional testing programs are required to enable this decision to be taken. For this reason, and based on the results from published efforts cited above, it has been decided to extend the study to additional materials but concentrating on the diametral $0.2 \mathrm{~mm}$ notched disc.

Figure 1 shows disc test specimen with a " $\mathrm{U}$ " shaped notch $0.2 \mathrm{~mm}$ deep in the axis plane of the disc $[2,14]$.

The first results of SP tests at lower temperatures carried out on 14 MoV6-3 steel indicated that the use of the notched specimens could shift the transition temperature $\mathrm{T}_{\mathrm{SP}}$ to higher temperatures to a limited extent but not to the much higher transition temperatures obtained using Charpy testing (Table 2 below). Beyond the maximum fracture energy, the temperature dependence of fracture energy was found also to be less steep (see Figure 2). 


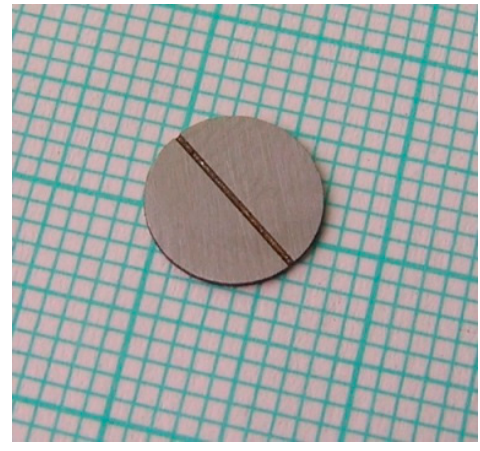

(a)

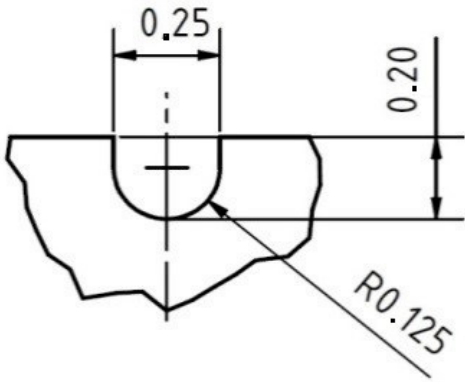

(b)

Figure 1. Disc test specimen with "U" notch in the axis of disc plane. (a) Figure of the disc specimen; (b) dimensions of the notch.

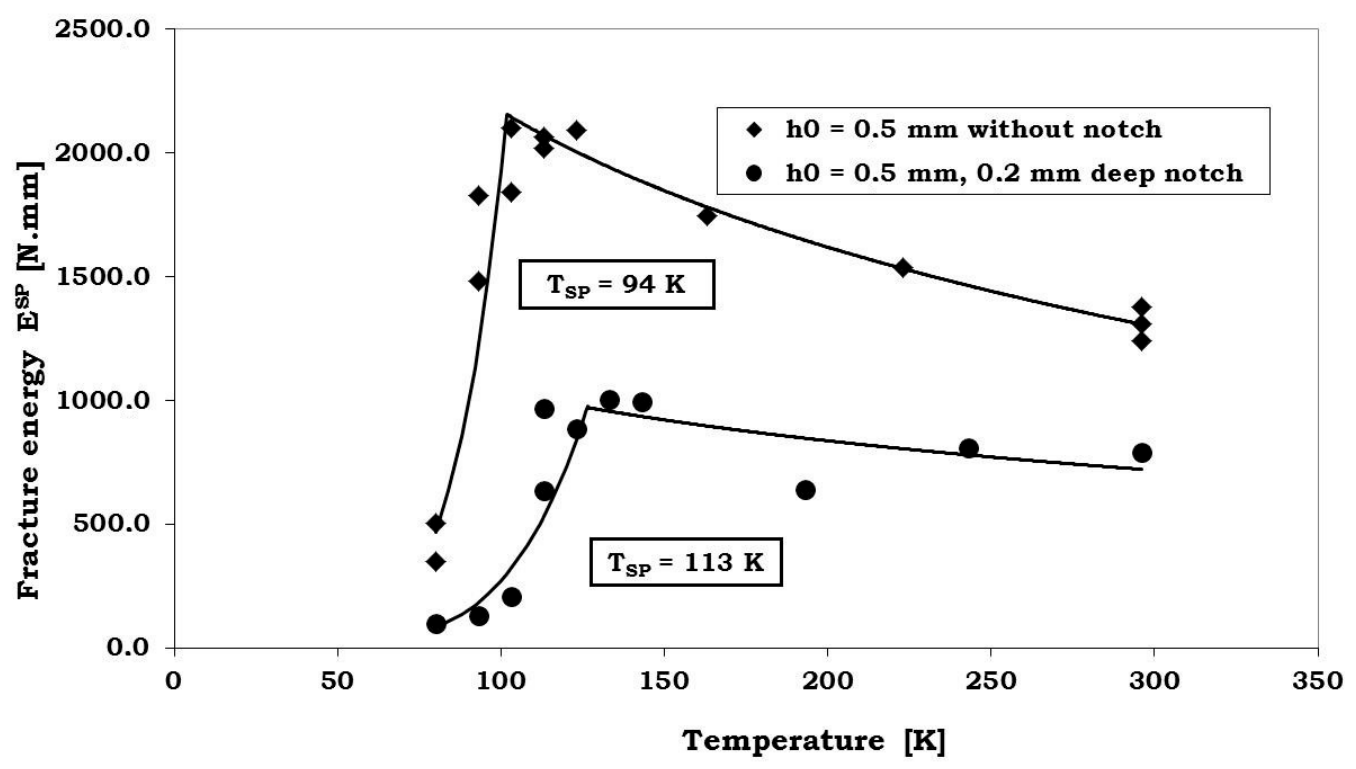

Figure 2. The effect of the notch on temperature dependence of fracture energy of penetration test. Pipe $\varnothing 457 \times 28 \mathrm{~mm}^{2}$ made of $14 \mathrm{MoV} 6-3$ steel after heat treatment $940{ }^{\circ} \mathrm{C} / 1 \mathrm{~h} /$ air $+720{ }^{\circ} \mathrm{C} / 2 \mathrm{~h} /$ air. Crosshead speed $1.5 \mathrm{~mm} \cdot \mathrm{min}^{-1}$, punch diameter $2.0 \mathrm{~mm}$ (adapted from [2] with permission of publisher).

In the present paper, these results will be compared with results obtained for tube $\varnothing$ $219 \times 22.2 \mathrm{~mm}^{2}$ in as received state made of P92 steel and tube $\varnothing 508 \times 25 \mathrm{~mm}^{2}$ in as received state made of P22 steel.

\section{Test Material}

Table 1 summarizes the controlled chemical composition of the testing materials.

Table 1. The chemical composition of studied materials (weight \%).

\begin{tabular}{cccccccccc}
\hline Material & C & Mn & Si & S & P & Cr & Mo & Ni & V \\
\hline 14MoV6-3 & 0.12 & 0.57 & 0.19 & 0.005 & 0.009 & 0.57 & 0.52 & 0.08 & 0.32 \\
P92 & 0.13 & 0.53 & 0.25 & 0.009 & 0.011 & 8.53 & 0.44 & 0.13 & 0.19 \\
P22 & 0.13 & 0.46 & 0.24 & 0.017 & 0.011 & 2.25 & 0.92 & 0.06 & 0.012 \\
\hline
\end{tabular}

Table 2 summarizes the tensile behavior at ambient temperature using round bars $8 \mathrm{~mm}$ in diameter. Test specimens were oriented in longitudinal direction. 
Table 2. Tensile behavior of testing material at ambient temperature.

\begin{tabular}{ccccc}
\hline Material & YS (Mpa) & UTS (Mpa) & A (\%) & Z (\%) \\
\hline P92 & 669 & 805 & 21.5 & 65 \\
P22 & 433 & 566 & 28.5 & 77 \\
14MoV6-3 & 403 & 536 & 30.3 & 83 \\
\hline
\end{tabular}

Microstructure of the P92 steel is composed of tempered martensite while microstructure of the P22 steel is tempered bainitic and the steel $14 \mathrm{MoV} 6-3$ is formed by mixture of tempered ferrite and bainite. Table 3 summarizes transition temperatures FATT and impact energies measured at FATT temperatures using Charpy V test specimens $(\mathrm{KV})_{\text {FATT }}$ and Charpy U test specimens $(\mathrm{KU})_{\text {FATT }}$ with notch $2 \mathrm{~mm}$ deep. All test specimens were oriented in tangential direction.

Table 3. Results of impact tests.

\begin{tabular}{cccc}
\hline Material & FATT $\left({ }^{\circ} \mathbf{C}\right)$ & $(\mathrm{KV})_{\text {FATT }}(\mathrm{J})$ & $(\mathrm{KU})_{\text {FATT }}(\mathrm{J})$ \\
\hline P92 & -3 & 62 & 89 \\
P22 & -1 & 74 & 136 \\
14MoV6-3 & -10 & 117 & 173 \\
\hline
\end{tabular}

Although the P92 steel has approximately the same FATT temperature as the steels P22 and $14 \mathrm{MoV} 6-3$ the fracture initiation energy $\left((\mathrm{KU})_{\mathrm{FATT}}-(\mathrm{KV})_{\mathrm{FATT}}\right)$ of this steel is significantly lower.

\section{Small Punch Test Results and Discussion}

SP tests at $-193{ }^{\circ} \mathrm{C}$ up to ambient temperature were carried out on the servo-mechanical testing machine Lab Test 5.10ST following the procedures set out in [1], under crosshead control at crosshead speed of $1.5 \mathrm{~mm} / \mathrm{min}$ with puncher $2 \mathrm{~mm}$ in diameter using discs $8 \mathrm{~mm}$ in diameter and $0.5 \pm$ $0.005 \mathrm{~mm}$ thickness. The load-cross head displacement curve was monitored during each SP test.

Figures 3 and 4 show the temperature dependences of the fracture energy $\mathrm{E}^{\mathrm{SP}}$ determined for P22 steel and P92 steel respectively using both plane disc specimens and disc specimens with the $0.2 \mathrm{~mm}$ deep notch. It can clearly be seen in Figure 3 that the increase in the small punch transition temperature for the P22 steel as a result of the introduction of the notch, namely from $89 \mathrm{~K}$ to $105 \mathrm{~K}$ is very similar to the result for the $14 \mathrm{MoV} 6-3$ shown in Figure 2. Again, the increase in value falls very much below the transition temperature obtained from the conventional Charpy test (Table 3). Whereas the SP Fracture energy / temperature curves for the un-notched 14M0V6-3 and P22 steels are almost identical, the notched P22 curve does not show a less steep dependence of fracture energy on temperature beyond the maximum energy, with the curve running in parallel to the un-notched results. A few repeat tests on the notched discs over the temperature range 90 to $130 \mathrm{~K}$ may clarify whether this minor difference between the P22 and 14MoV6-3 notched results is worthy of further investigation.

The fracture results for the P92 steel (Figure 4) are quite different to those for the other two alloys. The $\mathrm{T}_{\mathrm{SP}}$ of $146 \mathrm{~K}$ derived from the un-notched tests and the maximum fracture energy is reached around $170 \mathrm{~K}$, the transition part of the curve being much less steep than for 14MoV6-3 and P22 but reaching higher temperatures. This higher value for the SP transition temperature compares with the value of $133 \mathrm{~K}$ reported by Blagoeva et al. [16] for the comparable alloy P91. In comparison with the two lower alloy steels, there is no shift in the curve observed for the notched test at low temperatures, where the curve appears to follow exactly the same rise in fracture energy with temperature until around $150 \mathrm{~K}$, coincidentally around the $\mathrm{T}_{\mathrm{SP}}$ for the un-notched test, where the fracture energy commences its fall with further increase in temperature. A similar lack of displacement of the notched curve was also reported for alloy P91 but for $1 \mathrm{~mm}$ thick discs with and without $0.5 \mathrm{~mm}$ deep notches by Turba et al. [13]. As a result of this lack of displacement of the curve to higher temperatures, the $T_{\mathrm{SP}}$ for the P92 notched test is characterized by the lower value of $124 \mathrm{~K}$. In this case, the introduction of a 
notch played no role in increasing the SP transition temperature towards the Charpy value, in fact quite the reverse.

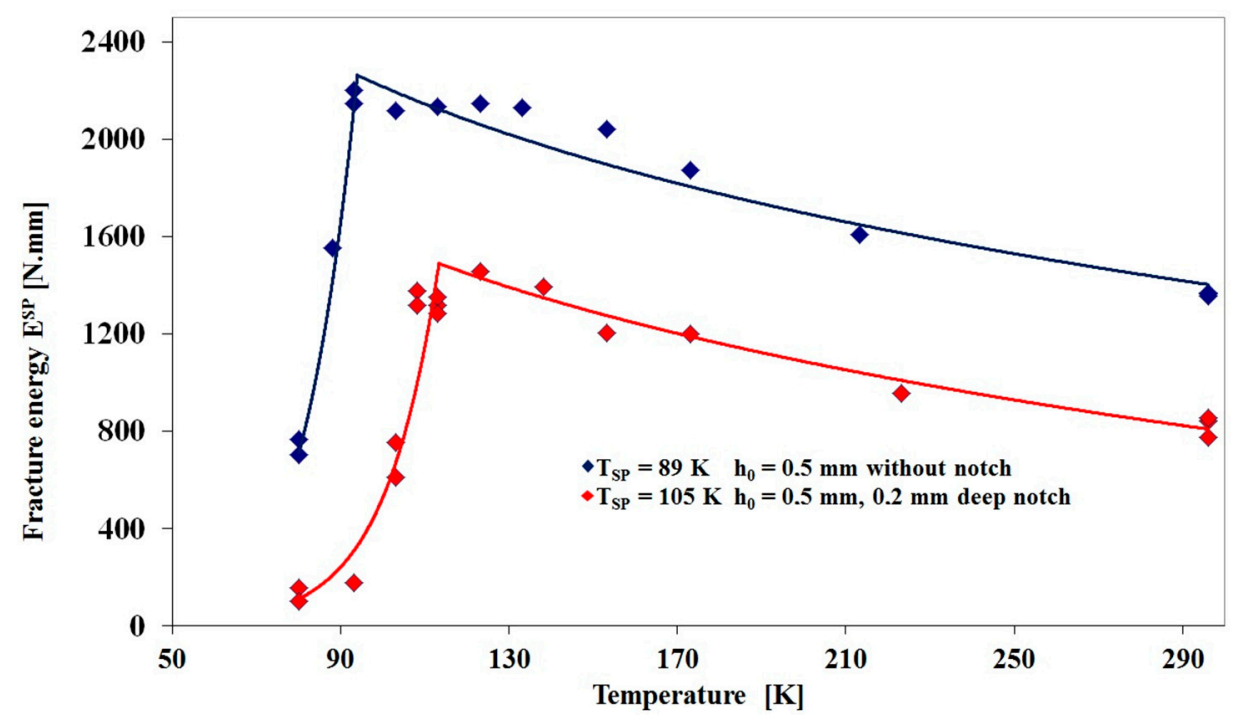

Figure 3. Temperature dependence of small punch transition temperature $\mathrm{T}_{\mathrm{SP}}$ determined for P22 steel using plane disc specimens $0.5 \mathrm{~mm}$ in thickness and disc specimens with $0.2 \mathrm{~mm}$ deep notch.

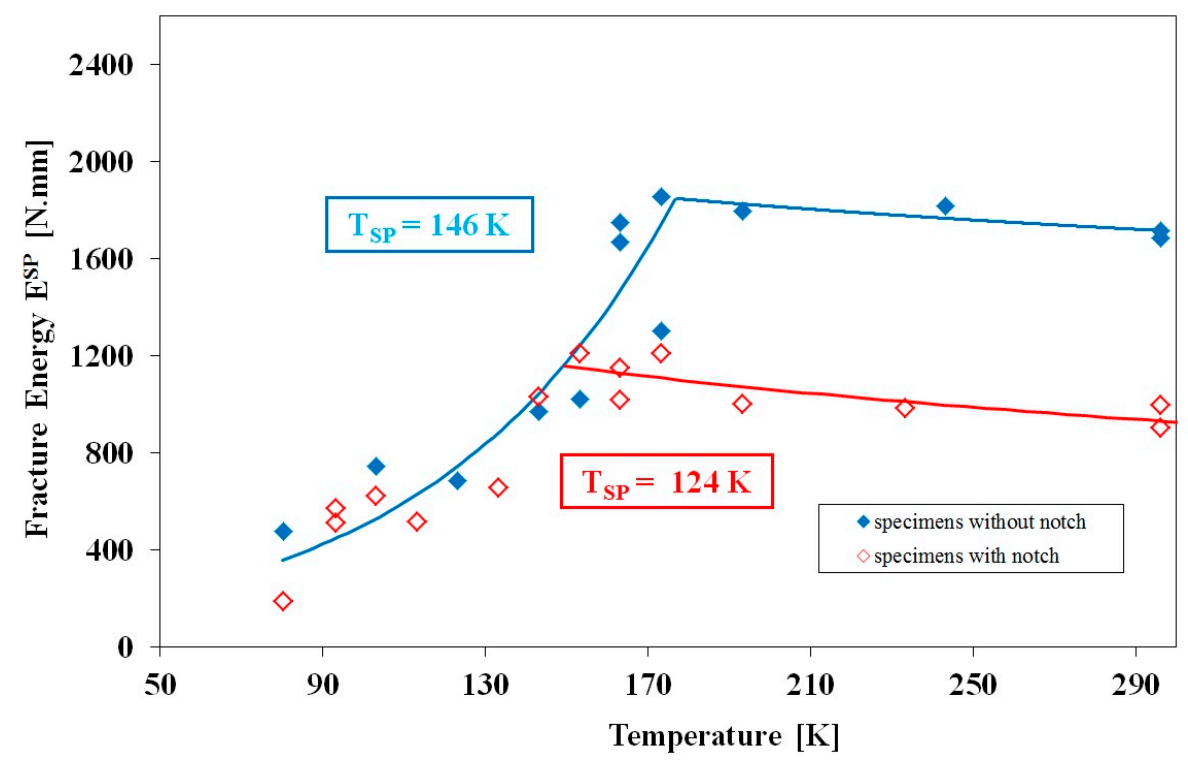

Figure 4. Temperature dependence of small punch transition temperature $\mathrm{T}_{\mathrm{SP}}$ determined for P92 steel using plane disc specimens $0.5 \mathrm{~mm}$ in thickness and disc specimens with $0.2 \mathrm{~mm}$ deep notch.

For all these types of notched SP test, it is important to understand the role played by the initiation of the crack and the energy for crack growth. Although the presence of the notch will undoubtedly play a role in crack initiation the results show that the effect of the notch in the Charpy test is much more dominant, indicating that the main effect in the notched SP test lies with the crack propagation. As a result, the transition temperatures found in the notched tests are not so much affected by the notch but the fracture energies are certainly reduced for the notched specimens. This could simply be caused by the difference in ligament length, $0.5 \mathrm{~mm}$ for the un-notched and $0.3 \mathrm{~mm}$ for the notched, through which the crack must propagate. This is also apparent in the results for P91 [13] where the fracture energy for a $1 \mathrm{~mm}$ thick disc is clearly greater than for a $0.5 \mathrm{~mm}$ thick disc. We intend to 
investigate this aspect in future work by testing plain discs of $0.3 \mathrm{~mm}$ thickness and notched specimens with $0.1 \mathrm{~mm}$ deep notches along with plain specimens of $0.4 \mathrm{~mm}$ thickness.

Of considerable importance in the application of SP fracture testing is the acceptance of plant operators whether they can rely on the $\alpha$ values obtained in predicting the FATT or DBTT properties for components, in particular where degradation in long term properties may be expected for example through irradiation, creep, or other microstructural damage. As Table 4 shows the ratio of $\mathrm{T}_{\mathrm{SP}} /$ FATT determined using plane discs is significantly dependent on the type of material, although the differences appear to be less for the notched discs. For this reason, it would still appear to be justifiable to include notched SP tests in the forthcoming EN standard although a much more fundamental understanding of the actual role of the notch is required.

Table 4. Ratios $\mathrm{T}_{\mathrm{SP}} /$ FATT obtained using both plane and notched discs.

\begin{tabular}{ccccc}
\hline Material & $\left(\mathrm{T}_{\text {SP }}\right)_{\text {plane }}[\mathrm{K}]$ & $\alpha=\left(\mathrm{T}_{\text {SP }}\right)_{\text {plane }} /$ FATT & $\left.\mathbf{( T}_{\text {SP }}\right)_{\text {notch }}[\mathrm{K}]$ & $\mathbf{A}=\left(\mathbf{T}_{\text {SP }}\right)_{\text {notch }} /$ FATT \\
\hline P92 & 146 & 0.54 & 124 & 0.46 \\
P22 & 89 & 0.33 & 105 & 0.39 \\
14MoV6-3 & 94 & 0.40 & 113 & 0.43 \\
\hline
\end{tabular}

\section{Conclusions}

On the basis of temperature dependences of small punch fracture energy $\mathrm{E}^{\mathrm{SP}}$ determined for P92, P22, and 14MoV6-3 steels with different microstructures using both plane and notched disc test specimens and impact tests for determination of FATT temperature it is possible to make the following conclusions:

(1) The introduction of a $0.2 \mathrm{~mm}$ U-shaped notch into a standard $0.5 \mathrm{~mm}$ SP disc specimen raises to a limited extent the measured ductile brittle transition temperature for P22 and 14MoV6-3 steels while marginally reducing the transition temperature for the P92 steel.

(2) This confirms the results of other workers looking at different sizes and shapes of notches and indeed different materials that it is not possible to raise the transition temperature using a notched $\mathrm{SP}$ disc to the levels measured in a conventional Charpy test.

(3) However, with increasing data being made available for the correlation of SP and Charpy fracture transition temperature using the relationship $\alpha=\left(\mathrm{T}_{\mathrm{SP}}\right)_{\text {notch }} / \mathrm{FATT}$, it is conceivable that the consistency of $\alpha$ values may be improved by obtaining them with notched SP tests and to this end these tests could usefully be introduced into the EN standard for SP testing presently in preparation.

Acknowledgments: Part of this paper was created in the Project No. LO1203 "Regional Materials Science and Technology Centre-Feasibility Program" funded by Ministry of Education, Youth and Sports of the Czech Republic.

Author Contributions: All authors contributed to research and writing this article. Karel Matocha coordinated the publication and was responsible together with Roger Hurst for interpretation of results. Ondrej Dorazil was responsible for sample preparation and small punch testing.

Conflicts of Interest: The authors declare no conflict of interest.

\section{References}

1. CEN WORKSHOP AGREEMENT. Small Punch Test Method for Metallic Materials; CWA 15627:2007 D/E/F; European Committee for Standardization: Brussels, Belgium, 2007.

2. Hurst, R.; Matocha, K. Determination of Mechanical Properties of Materials by Small Punch and other Miniature Testing Techniques Tensile and Fracture Behaviour. In Proceedings of the 3rd International Conference SSTT, Castle Seggau near Graz, Austria, 23-25 September 2014; pp. 1-26. 
3. Hurst, R.C.; Matocha, K. Determination of Mechanical Properties of Materials by Small Punch and other Miniature Testing Techniques. In Proceedings of the 1st International Conference SSTT, Ostrava, Czech Republic, 31 August-2 September 2010; pp. 5-11.

4. Hurst, R.; Matocha, K. Determination of Mechanical properties of Materials by Small Punch and other Miniature Testing Techniques. In Proceedings of the 2nd International Conference SSTT, Ostrava, Czech Republic, 2-4 October 2012; pp. 4-18.

5. Ha, J.S.; Fleury, E. Small punch tests to estimate the mechanical properties of steels for steam power plant: II. Fracture toughness. Int. J. Press. Vessel. Pip. 1998, 75, 707-7013. [CrossRef]

6. Foulds, J.R.; Viswanathan, R. Small punch testing for determining the material toughness of low alloy components in service. J. Eng. Mater. Technol. 1994, 116, 457-464. [CrossRef]

7. Turba, K.; Hurst, R.; Hähner, P. Determination of Mechanical Properties by Small Punch and other Miniature Testing Techniques. In Proceedings of the 2nd International Conference SSTT, Ostrava, Czech Republic, 2-4 October 2012; pp. 196-202.

8. Matocha, K. Determination of Actual Tensile and Fracture Characteristics of Critical Components of Industrial Plants under Long Term Operation by SPT. In Proceedings of the ASME 2012 Pressure Vessels \& Piping Division Conference, Toronto, ON, Canada, 2012; pp. 15-19.

9. Matocha, K. Small Punch Testing for Tensile and Fracture Behaviour-Experiences and way forward. In Small Specimen Test Techniques: 6th Volume; ASTM STP1576; ASTM International: West Conshohocken, PA, USA, 2015; pp. 145-159.

10. Ju, J.-B.; Jang, J.; Kwon, D. Evaluation of fracture toughness by small-punch testing techniques using sharp notched specimens. Int. J. Press. Vessel. Pip. 2003, 80, 221-228. [CrossRef]

11. Cuesta, I.I.; Rodriguez, C.; Belzunce, F.J.; Alegr, J.M. Analysis of different techniques for obtaining pro-cracked/notched small punch test specimens. Eng. Fail. Anal. 2011, 18, 2282-2287. [CrossRef]

12. Lacalle, R.; Álvarez, J.A.; Cicero, S.; Gutiérrez-Solana, F. From Archaeology to Precious Metals: Four Applications of Small Punch test. Metall. J. 2010, 63, 59-68.

13. Turba, K.; Gůlcimen, B.; Li, Y.; Blagoeva, D.; Hähner, P.; Hurst, R. Introduction of a new notched specimen geometry to determine fracture properties by small punch testing. Eng. Fract. Mech. 2011, 78, 2826-2833. [CrossRef]

14. Adams, J.; Bache, M.R.; Hurst, R.C.; Borradaile, J.B. Determination of Mechanical Properties of Materials by Small Punch and other Miniature Testing Techniques. In Proceedings of the 3rd International Conference SSTT, Castle Seggau near Graz, Austria, 23-25 September 2014; pp. 1-26.

15. Adams, J. Development of Small Specimen Test Techniques for Toughness Measurement. Ph.D. Thesis, University of Swansea, Swansea, UK, 2015.

16. Blagoeva, D.; LI, Y.Z.; Hurst, R.C. Qualification of P91 welds through small punch creep testing. J. Nucl. Mater. 2011, 409, 124-130. [CrossRef]

(C) 2017 by the authors. Licensee MDPI, Basel, Switzerland. This article is an open access article distributed under the terms and conditions of the Creative Commons Attribution (CC BY) license (http:/ / creativecommons.org/licenses/by/4.0/). 